\title{
Karakterisasi Struktur Material Pasir Bongkahan Galian Golongan C Dengan Menggunakan X-Ray Difraction (X-RD) Di Kota Palangkaraya
}

\author{
Luqman Hakim $^{1 *}$, Made Dirgantara' ${ }^{1}$ dan Muhammad Nawir ${ }^{2}$ \\ ${ }^{1}$ Program Studi Fisika, Universitas Palangka Raya, Indonesia $73112 \mathrm{~A}$ \\ ${ }^{2}$ Program Studi Pendidikan Fisika, Universitas Palangka Raya, Indonesia $73112 \mathrm{~A}$ \\ *luqman_h@mipa.upr.ac.id
}

\begin{abstract}
Abstrak
Telah dilakukan Karakterisasi Struktur Material Pasir Bongkahan Galian Golongan C Dengan Menggunakan X-Ray Difraction (X-RD). Karakterisasi fisis material menggunakan X-Ray Diffraction (XRD) bertujuan mengetahui komposisi mineral dengan melihat intensitas pada sudut $2 \theta$ yang karakteristik untuk setiap senyawa. X-RD yang digunakan adalah model Rigaku Miniflex 600 Benchop X-Ray Diffraction (XRD) (F.F tube 40kV, $15 \mathrm{~mA}$ ) dengan detector Scintillation counter (K $\beta$ filter) dilakukan dari 2 teta $10^{\circ}-80^{\circ}$. Analisis XRD dilakukan dengan menggunakan aplikasi High Score PlusVersi 3.0e. Objek penelitian ini adalah pasir bongkahan dengan variasi perbedaaan warna, yaitu . yaitu kecoklatan, hitam dan hitam pekat. Bongkahan pasir berasal dari galian golongan C di kota Palangka Raya yang diambil dari lokasi penambangan Jalan Tjilik Riwut km.18 dan Lokasi Penambangan Kelampangan. Untuk mengetahui kandungan mineral dalam suatu bahan tambang digunakan peralatan X-RD. Penggunaan X-RD cukup tepat karena X-RD bisa memberikan informasi mengenai struktur material dan nilai sudut kristalnya. X-RD bekerja berdasarkan difraksi sinar X yang dihamburkan oleh sudut kristal material yang dianalisa. Hasil dari penelitian ini adalah memberikan informasi mengenai kandungan material dan nilai sudut kristal yang terukur. Dengan adanya informasi struktur material diharapkan dapat digunakan sebagai informasi awal untuk penerapan dibidang kajian lainnya
\end{abstract}

Kata kunci: Material, Tambang golongan C, Bongkahan pasir, X-RD

\section{Pendahuluan}

Berdasarkan undang-undang Minerba No.4 Tahun 2009, pertambangan adalah sebagian atau seluruh tahapan kegiatan dalam rangka penelitian, pengelolaan dan pengusahaan mineral atau batubara yang meliputi penyelidikan umum, eksplorasi, studi kelayakan, konstruksi, penambangan, pengolahan dan pemurnian, pengangkutan dan penjualan, serta kegiatan pascatambang. Mineral adalah senyawa anorganik yang terbentuk di alam, yang memiliki sifat fisik dan kimia tertentu serta susunan kristal teratur atau gabungannya yang membentuk batuan, baik dalam bentuk lepas atau padu. Bahan tambang digolongkan menjadi 3, yaitu : golongan A, golongan B dan golongan $\mathrm{C}$ [1]. Bahan tambang golongan A adalah bahan galian strategis, bahan golongan $\mathrm{B}$ adalah bahan galian vital dan golongan $\mathrm{C}$ adalah bahan galian selain golongan $\mathrm{A}$ dan golongan B.

Kota Palangka Raya merupakan daerah yang secara umum berada dilahan gambut [2]. Bahan mineral/tambang yang di ekplorasi dikota Palangka Raya lebih banyak golongan C. Pemanfaatan bahan galian golongan $\mathrm{C}$ di Kota Palangka Raya lebih dominan pada pembangunan dan pengurukan jalan. Oleh karena itu diperlukan kajian terhadap struktur material agar dapat dimanfaatkan dibidang lain. Salah satu teknik pengkajian struktur material adalah dengan menggunakan X-RD [3].

$X$-Ray Diffraction (XRD) merupakan analisis yang digunakan untuk mengidentifikasi material kristalit, sebagai contoh identifikasi struktur kristalit (kualitatif) dan fasa (kuantitatif) dalam suatu bahan dengan memanfaatkan radiasi gelombang elektromagnetik sinar-X. Selain itu, juga dimanfaatkan untuk mengetahui rincian lain seperti susunan berbagai jenis atom dalam kristal, kehadiran cacat, orientasi, dan cacat kristal [4]. 
X-Ray Diffraction (XRD) merupakan analisis yang digunakan untuk mengidentifikasi material kristalit, sebagai contoh identifikasi struktur kristalit (kualitatif) dan fasa (kuantitatif) dalam suatu bahan dengan memanfaatkan radiasi gelombang elektromagnetik sinar-X [5]. Selain itu, juga dimanfaatkan untuk mengetahui rincian lain seperti susunan berbagai jenis atom dalam kristal, kehadiran cacat, orientasi, dan cacat kristal

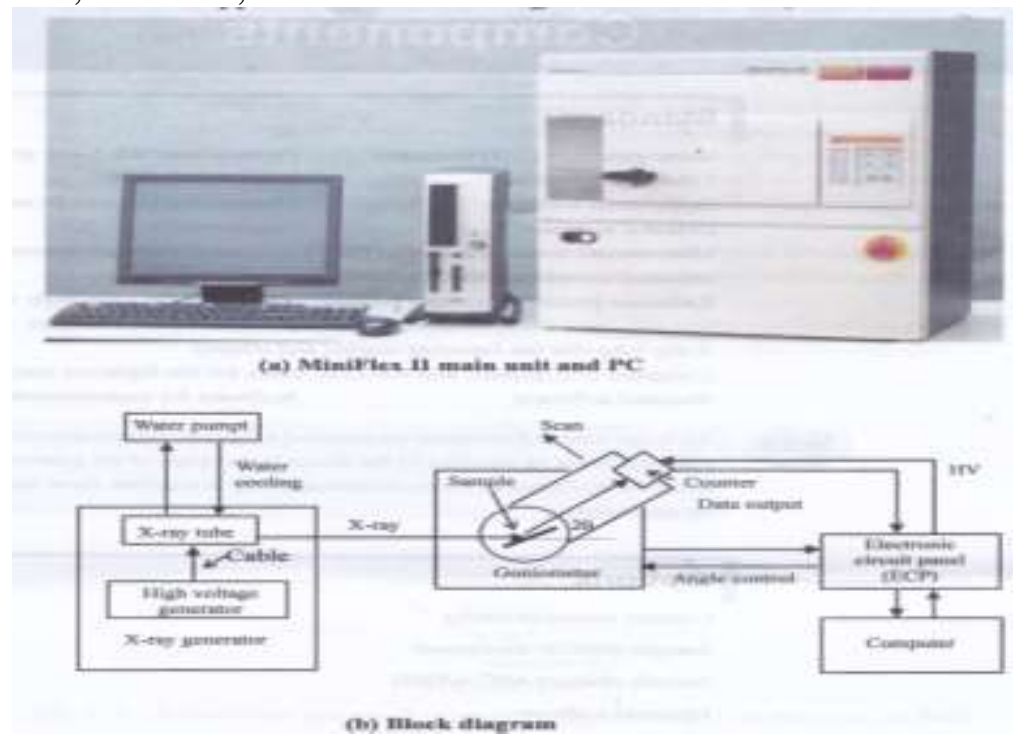

Gambar 1. XRD Rigaku MiniFlex II dan Diagram Blok Alat

Penentuan struktur kristal dapat dilakukan dengan metode difraksi. Difraksi adalah suatu metode experimen hamburan elastis, dimana proses transfer/perubahan energi dapat diabaikan dalam proses hamburan tersebut. Informasi yang diperoleh dari metode difraksi ini yakni data koordinat atom-atom dalam kristal yang mendasari sifat dan karakteristik bahan pada umumnya [5]. XRD digunakan untuk analisis komposisi fasa atau senyawa pada material dan juga karakterisasi kristal. Prinsip dasar XRD adalah mendifraksi cahaya yang melalui celah kristal. Difraksi cahaya oleh kisi-kisi atau kristal ini dapat terjadi apabila difraksi tersebut berasal dari radius yang memiliki panjang gelombang yang setara dengan jarak antar atom, yaitu sekitar 1 Angstrom. Radiasi yang digunakan berupa radiasi sinar-X, elektron, dan neutron. Sinar-X merupakan foton dengan energi tinggi yang memiliki panjang gelombang berkisar antara 0.5 sampai 2,5 amstrong. Ketika berkas sinar-X berinteraksi dengan suatu material, maka sebagian berkas akan diabsorbsi, ditransmisikan, dan sebagian lagi dihamburkan terdifraksi. Hamburan terdifraksi inilah yang dideteksi oleh XRD. Berkas sinar X yang dihamburkan tersebut ada yang saling menghilangkan karena fasanya berbeda dan ada juga yang saling menguatkan karena fasanya sama. Berkas sinar X yang saling menguatkan itulah yang disebut sebagai berkas difraksi. Hukum Bragg merumuskan tentang persyaratan yang harus dipenuhi agar berkas sinar $\mathrm{X}$ yang dihamburkan tersebut merupakan berkas difraksi. Ilustrasi difraksi sinar-X pada XRD dapat dilihat pada Gambar 2 dan Gambar 3. [3]-[6] 


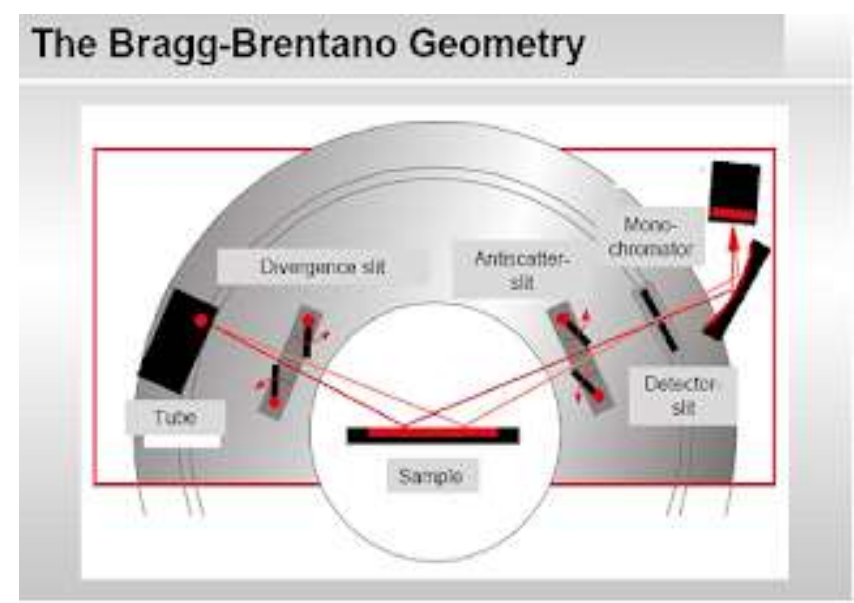

Gambar 2 : Difraksi sinar-X pada XRD

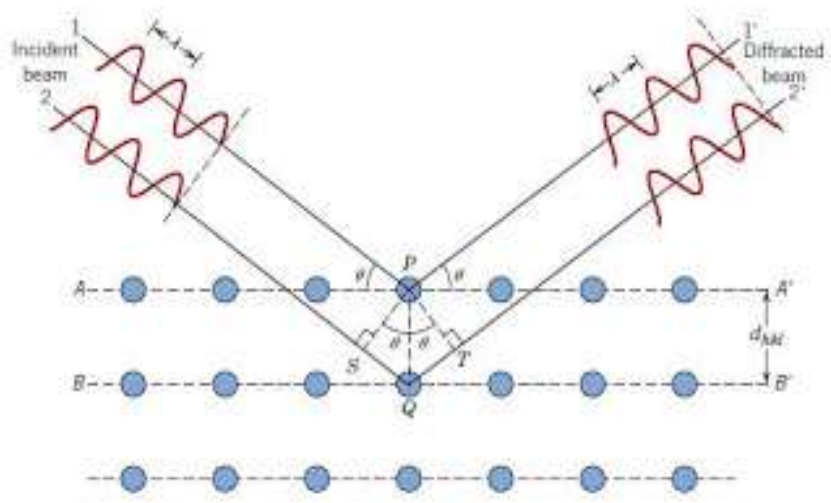

Gambar 3 : Ilustrasi difraksi sinar-X

Dari Gambar 3 dapat dideskripsikan sebagai berikut. Sinar datang yang menumbuk pada titik pada bidang pertama dan dihamburkan oleh atom P. Sinar datang yang kedua menumbuk bidang berikutnya dan dihamburkan oleh atom Q, sinar ini menempuh jarak SQ + QT bila dua sinar tersebut paralel dan satu fasa (saling menguatkan). Jarak tempuh ini merupakan kelipatan (n) panjang gelombang $(\lambda)$, sehingga persamaan menjadi (Callister,2003):

dimana

$$
n \lambda=2 d_{h k l} \sin \theta
$$

$\lambda \quad=$ panjang gelombang sinar-x $(1 \mathrm{Cu}=1,540562 \AA ̊)$

$\theta \quad=$ sudut difraksi yang menggambarkan posisi puncak

$\mathrm{d}_{\mathrm{hkl}} \quad=$ jarak antar bidang yang menggambarkan sistem, ukuran sel satuan dan indeks

Miller bidang tersebut

Analisis struktur material diperlukan untuk mengidentifikasi material tersebut dan sebagai tindak lanjut untuk pemanfaatanya. Dalam penelitian ini akan dilakukan analisis struktur material golongan $\mathrm{C}$ khusunya bongkahan padat pada pasir urug di kota Palangka Raya. Penelitian ini bertujuan untuk mengetahui struktur dan kandungan material yang terkandung pada bahan material tambang pasir yang ada di Kota Palangkaraya.

\section{Metote Penelitian}

Bahan uji pada penelitian ini meliputi bongkahan pasir yang diambil dari tempat penambangan golongan $\mathrm{C}$ di kota Palangka Raya yang berupa bongkahan pasir. Bongkahan pasir diambil dari tempat penambangan jalan Tjilik Riwut km 18 dan penambangan di Kalampangan. Alat penelitian 
yaitu X-Ray Diffraction (Rigaku MiniFlex II), Mortar diameter $15 \mathrm{~cm}$ sebagai penghalus, ayakan 100 mesh. X-Ray Diffraction (XRD) untuk mengetahui komposisi mineral dengan melihat intensitas pada sudut $2 \theta$ yang karakteristik untuk setiap senyawa. Untuk mengetahui struktur mineral pada pasir bongkahan dapat dilihat dari hasil pengujian XRD, dimana setiap bahan memiliki karakteristik panjang gelombang yang berbeda.

Pengujian XRD dilakukan di Laboratorium Kimia Universitas Negeri Yogyakarta dengan alat XRD model Rigaku Miniflex 600 Benchop X-Ray Diffraction (XRD) (F.F tube 40kV, $15 \mathrm{~mA}$ ) dengan detector Scintillation counter $\left(\mathrm{K} \beta\right.$ filter) dilakukan dari 2 teta $10^{\circ}-80^{\circ}$. Analisis XRD dilakukan dengan menggunakan aplikasi High Score PlusVersi 3.0e yang diproduksi oleh PANalytical B.V. Almelo, The Netherlands.

\section{Hasil dan Pembahasan}

\section{Preparasi Sampel}

Sampel yang diujikan adalah bongkahan pasir urug yang diambil dari 2 lokasi penambangan di kota Palangkaraya, yaitu penambangan di Jalan Tjilik Riwut km.18 (Gambar 4) dan Kelampangan (Gambar 5). Sampel sipisahkan berdasarkan warna, kemudian dikeringkan dengan suhu lingkungan selama 2 minggu untuk mengurangi kadar air dalam sampel. Setelah sampel kering sampel digerus dengan mortar sampai halus dan diayak 60 mesh.
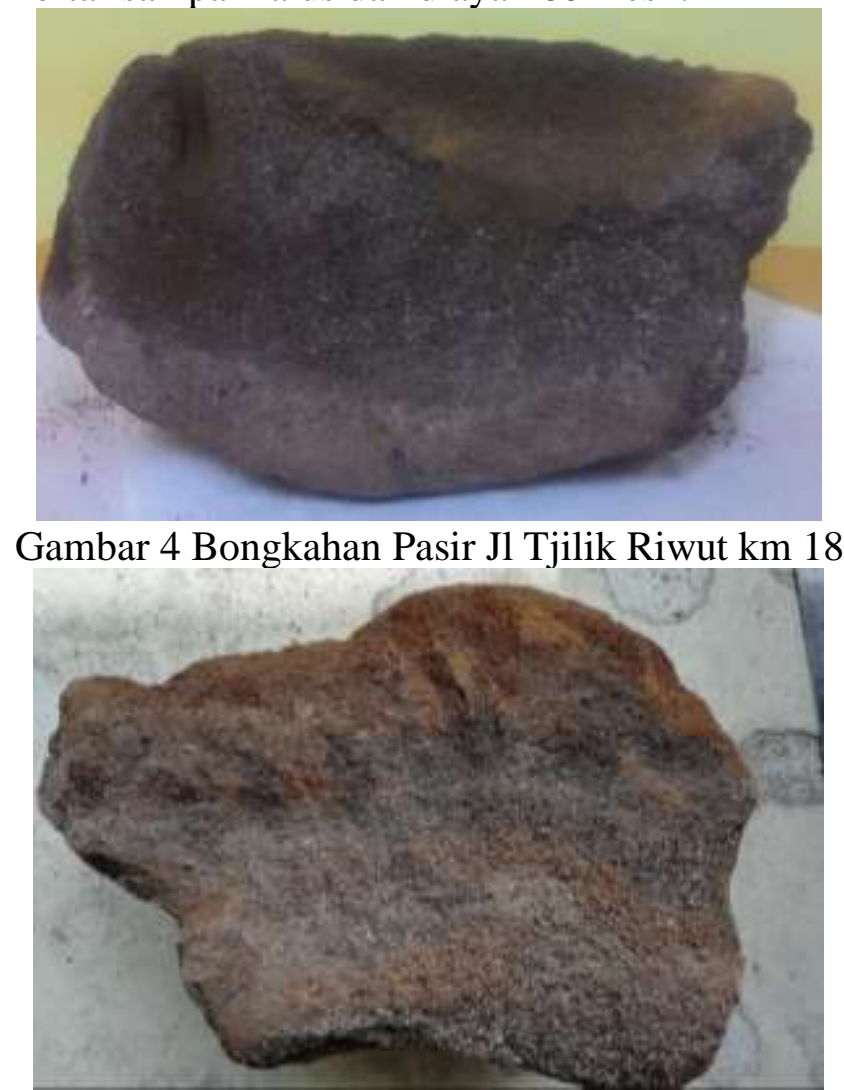

Gambar 5 Bongkahan Pasir Kelampangan

Hasil Uji XRD Bongkahan Pasir Jl. Tjilik Riwut Km. 18

Lokasi penambangan pasir di sekitar jalan Tjilik Riwut km.18 merupakan lahan rawa basah yang berdekatan dengan aliran anak sungai. Hasil uji dan analisis dengan menggunakan X-RD dari bongkahan pasir urug berdasarkan warna diperoleh seperti gambar 6, gambar 7 dan gambar 8 . 


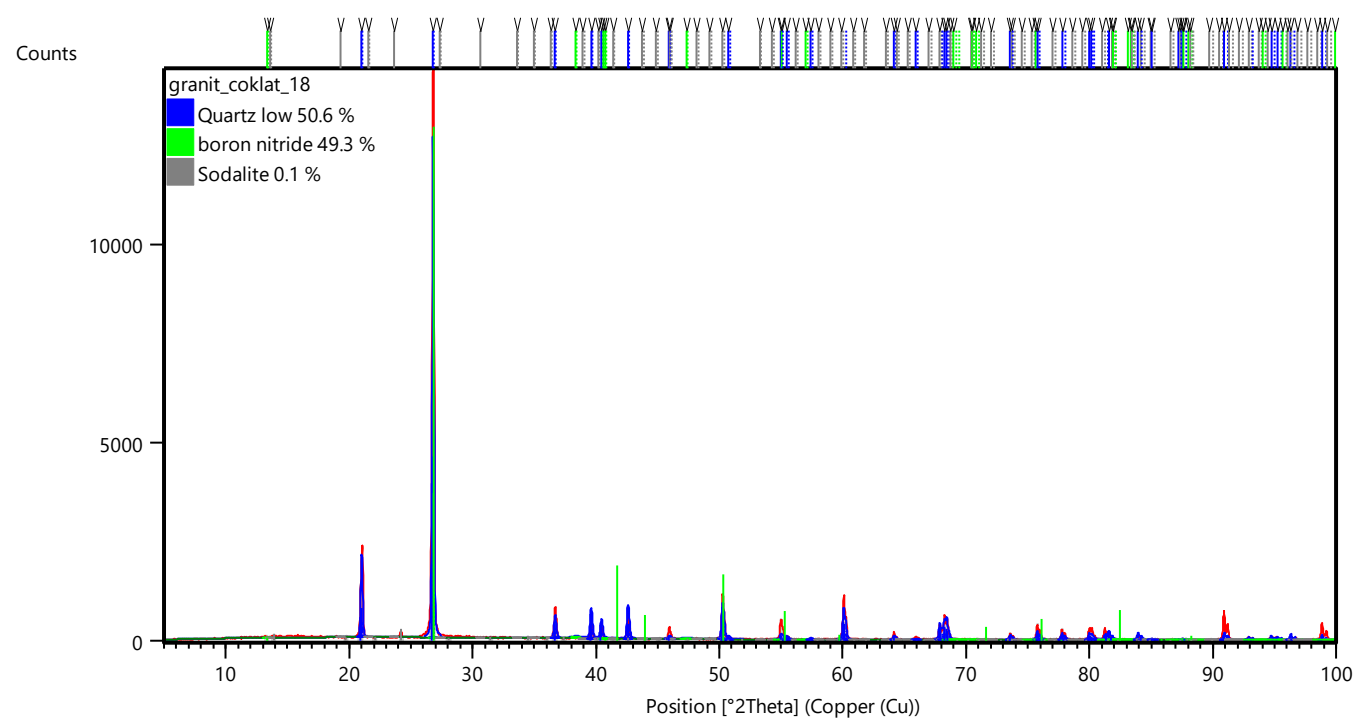

Gambar 6 Hasil Uji XRD Bongkahan Pasir Jl. Tjilik Riwut km.18 Warna Cokelat

Bongkahan pasir yang berasal dari penambangan jalan Tjilik Riwut km.18, pada bagian berwarna coklat memiliki 3 komponen terdiri dari Quartz Low dengan persentase 50.6\%, Boron Nitride dengan persentase $49.3 \%$ dan Sodalite dengan persentase $0.1 \%$. Pada bongkahan ini, sudut hambur $2 \theta$ memiliki puncak tertinggi pada sudut $27^{0}$.

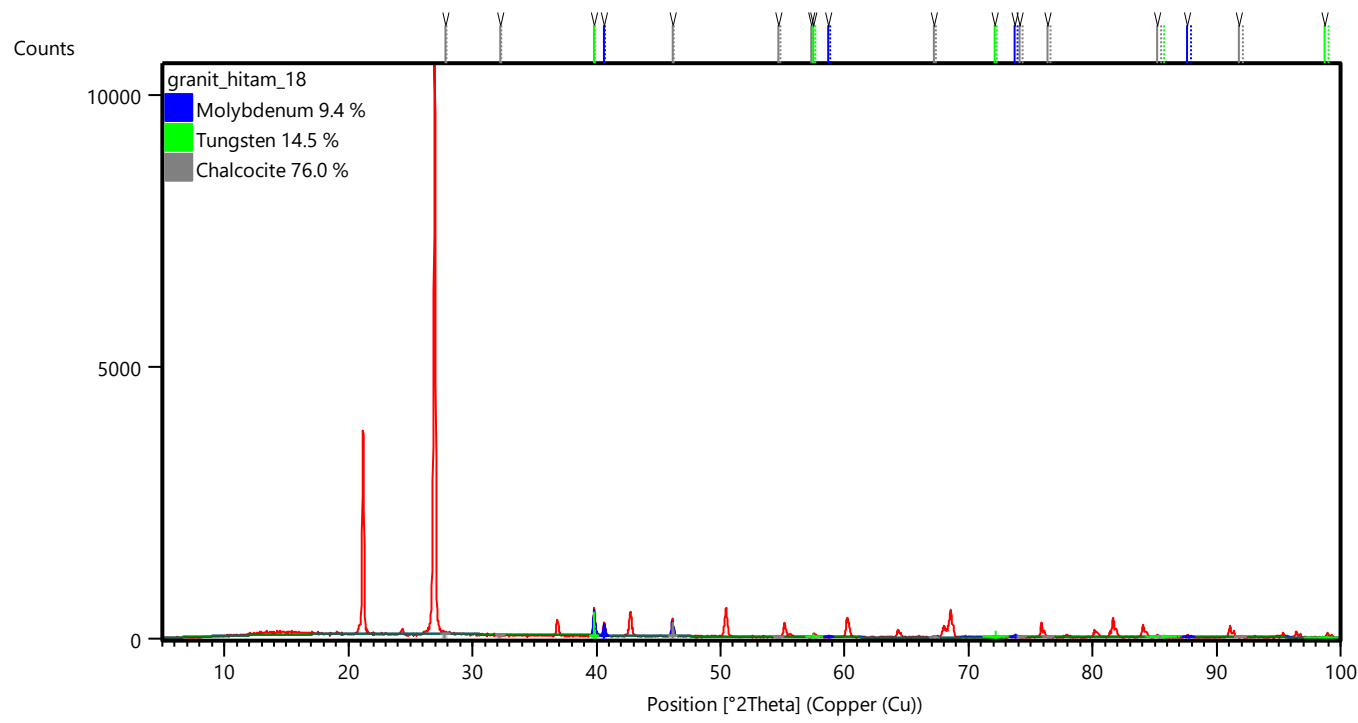

Gambar 7 Hasil Uji XRD Bongkahan Pasir Jl. Tjilik Riwut km.18 Warna Hitam

Bongkahan pasir yang berasal dari penambangan jalan Tjilik Riwut km.18, pada bagian berwarna hitam memiliki 3 komponen terdiri dari Chalcocite dengan persentase $76.0 \%$, Tungsten dengan persentase $14.5 \%$ dan Molybdenum dengan persentase 9.4\%. Pada bongkahan ini, sudut hambur $2 \theta$ memiliki puncak tertinggi pada sudut $27^{\circ}$. 


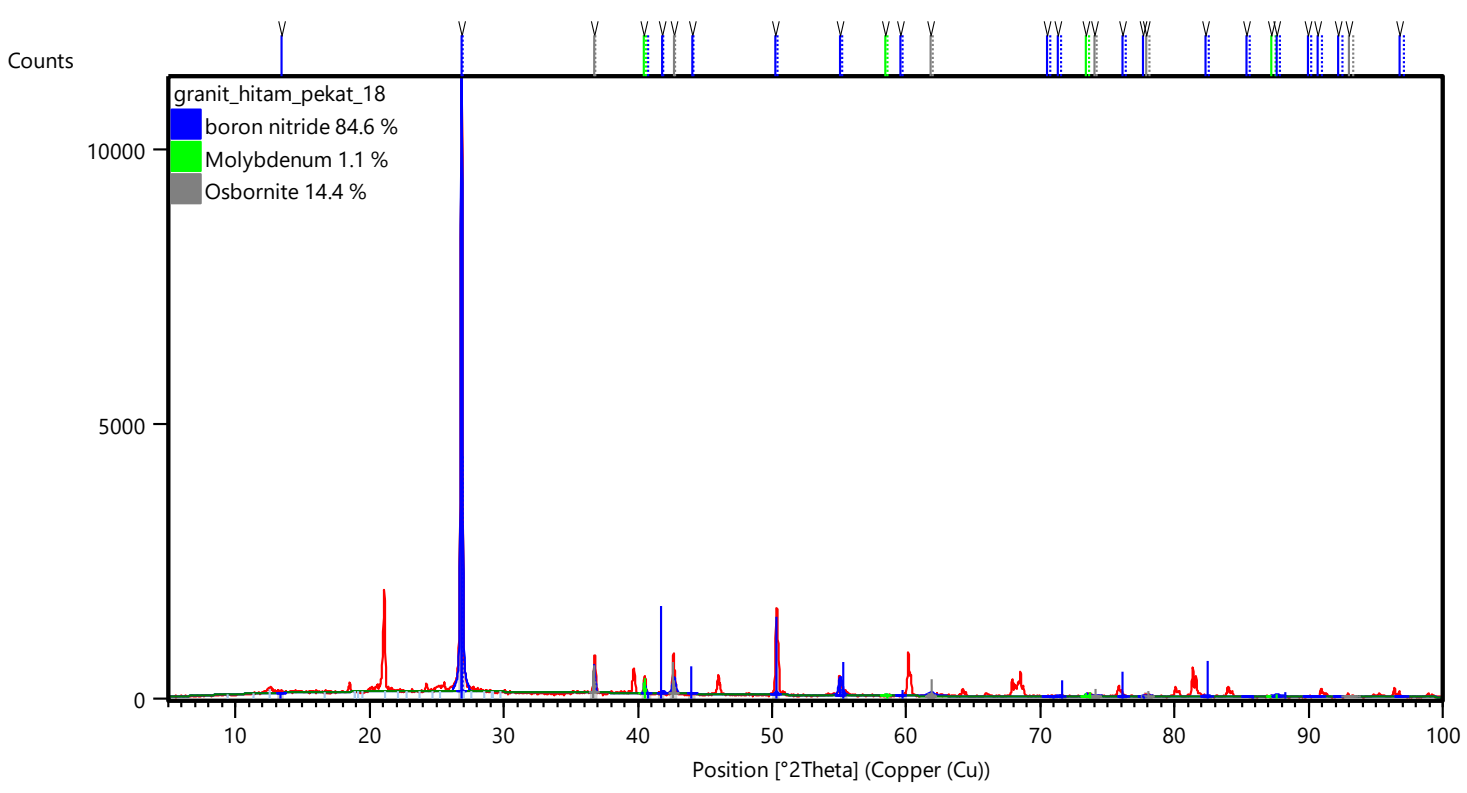

Gambar 8 Hasil Uji XRD Bongkahan pasir Jl. Tjilik Riwut km.18 Warna Hitam Pekat

Bongkahan pasir yang berasal dari penambangan jalan Tjilik Riwut km.18, pada bagian berwarna hitam pekat memiliki 3 komponen terdiri dari Boron nitride dengan persentase $84.6 \%$, Osbornite dengan persentase $14.4 \%$ dan Molybdenum dengan persentase $1.1 \%$. Pada bongkahan ini, sudut hambur $2 \theta$ memiliki puncak tertinggi pada sudut $27^{\circ}$.

\section{Hasil Uji XRD Bongkahan Pasir Kelampangan}

Lokasi penambangan pasir di Kelampangan merupakan lahan rawa basah yang berjahan dengan sungai. Hasil uji dan analisis dengan menggunakan X-RD dari bongkahan pasir urug Kelampangan berdasarkan warna diperoleh seperti gambar 6, gambar 7 dan gambar 8 .

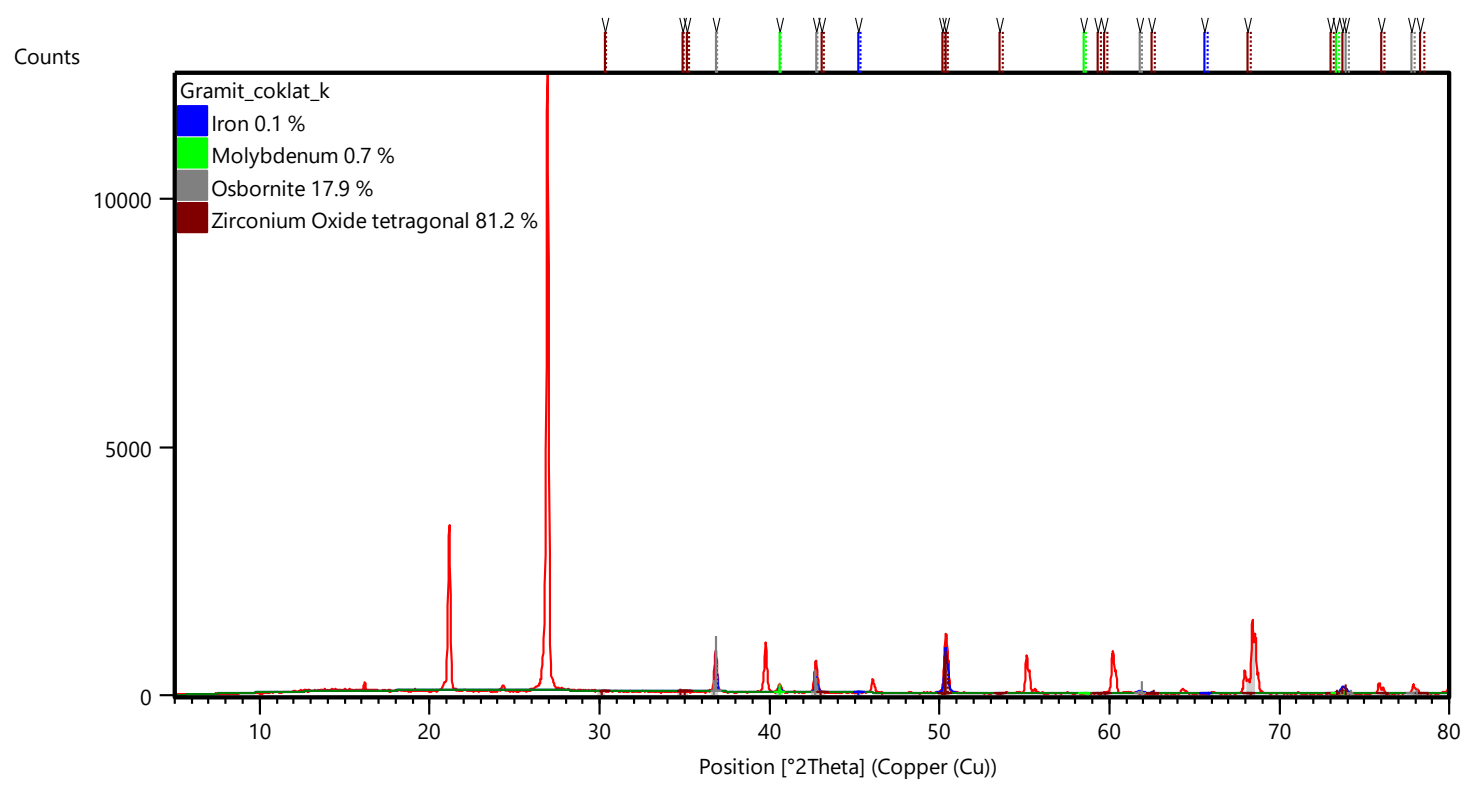

Gambar 1 Hasil Uji XRD Bongkahan Pasir Kelampangan Warna Cokelat

Bongkahan pasir yang berasal dari penambangan pasir Kelampangan , pada bagian berwarna cokelat memiliki 4 komponen terdiri dari Zirkonium Oxide tetragonal dengan persentase 81.2\%, 
Osbornite dengan persentase $17.9 \%$, Molybdenum dengan persentase $0.7 \%$ dan Iron $0.1 \%$. Pada bongkahan ini, sudut hambur $2 \theta$ memiliki puncak tertinggi pada sudut $27^{\circ}$.

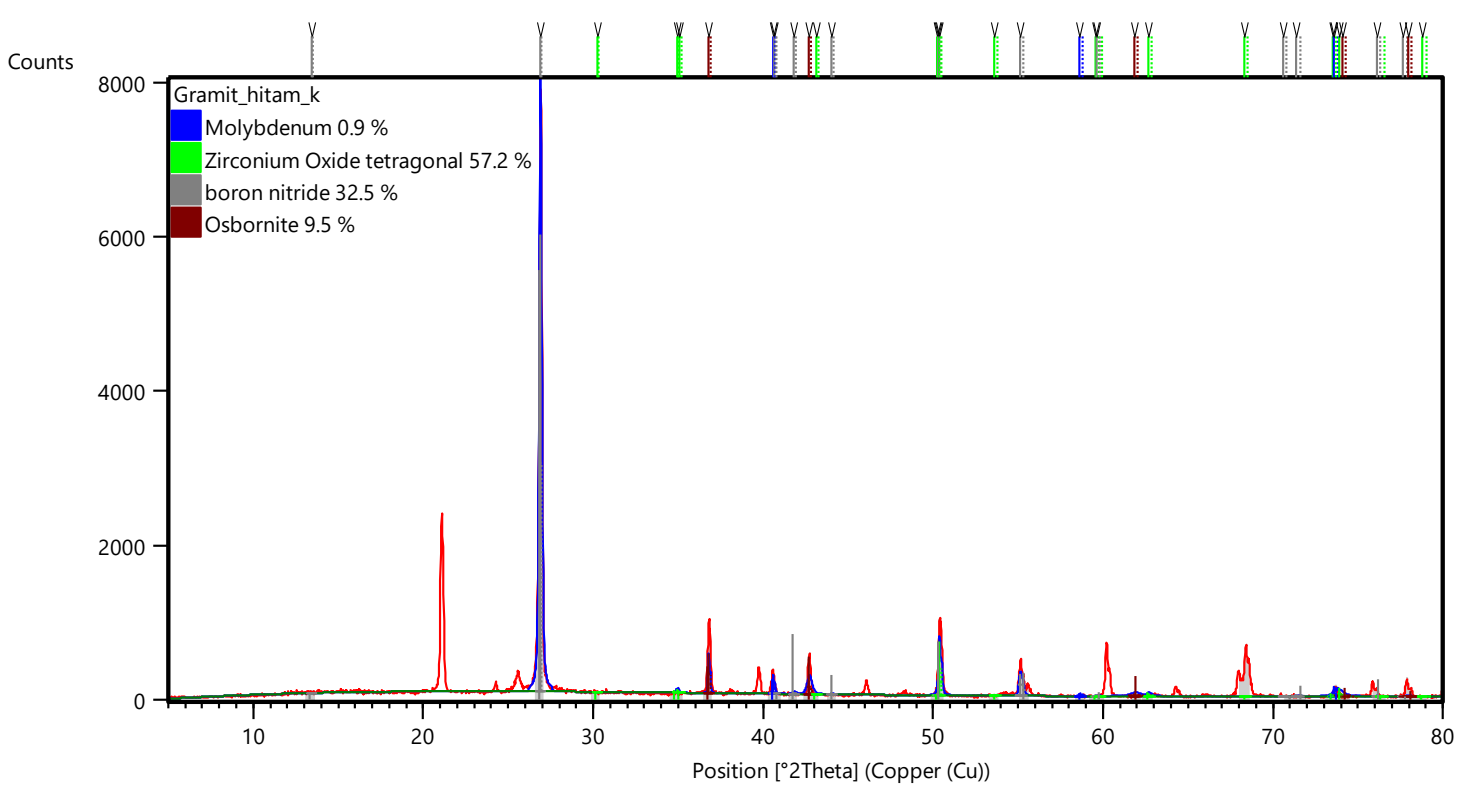

Gambar 2 Analisis XRD Bongkahan Pasir Kelampangan Warna Hitam

Bongkahan pasir yang berasal dari penambangan pasir Kelampangan, pada bagian berwarna hitam memiliki 4 komponen terdiri dari Zirkonium Oxide tetragonal dengan persentase $57.2 \%$, Boron nitride dengan persentase $32.5 \%$, Osbornite dengan presentase kandungan 9.5\% dan Molybdenum dengan persentase $0.9 \%$. Pada bongkahan ini, sudut hambur $2 \theta$ memiliki puncak tertinggi pada sudut $27^{0}$.

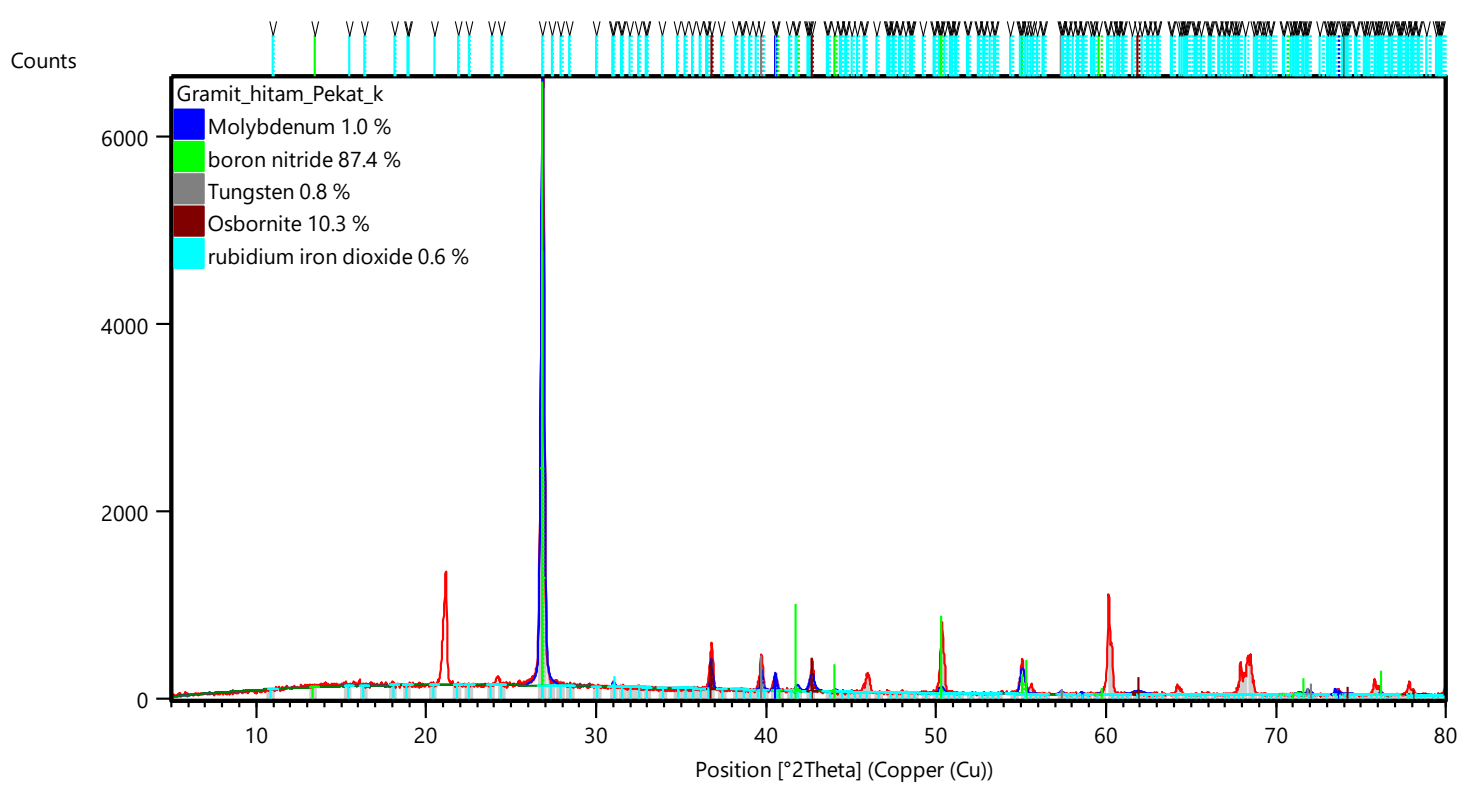

Gambar 3 Analisis XRD Bongkahan Pasir Kelampangan Warna Hitam Pekat

Bongkahan pasir yang berasal dari penambangan pasir Kelampangan, pada bagian berwarna hitam pekat memiliki 5 komponen terdiri dari boron nitride dengan persentase 87.4\%, Osbornite dengan presentase $10.3 \%$, Molybdenum dengan persentase $1.0 \%$, Tungsten dengan presentase $0.8 \%$ dan rubidium iron dioxide $0.6 \%$. Pada bongkahan ini, sudut hambur $2 \theta$ memiliki puncak tertinggi pada sudut $27{ }^{0} \mathrm{C}$. 


\section{Kesimpulan}

Kandungan mineral dalam suatu bahan tambang dapat diketahui dengan menggunakan peralatan X-RD. Penggunaan X-RD cukup tepat karena X-RD bisa memberikan informasi mengenai struktur material dan nilai sudut kristalnya. X-RD bekerja berdasarkan difraksi sinar $\mathrm{X}$ yang dihamburkan oleh sudut kristal material yang dianalisa. Hasil dari penelitian ini memberikan informasi mengenai kandungan material dan nilai sudut kristal yang terukur.

\section{Referensi}

[1] M. M. D. Widiastuti dan G. Samderubun, "Policy Strategy to Overcome Beach Sand Mining in The Nasai Beach - Merauke Regency," J Kebijak. Sosek KP, vol. 8, no. 1, hlm. 13-26, 2018.

[2] W. Febriani, B. S. Anggoro, R. Komala, dan S. Agustina, "Explorasi Dan Identifikasi Hijauan Potensial Di Lahan Gambut Kotawaringin Barat Kalimantan Tengah,” Biosf. J. Tadris Biol., vol. 9, no. 1, hlm. 100-113, Agu 2018.

[3] D. Wulansari, L. D. Setijadji, dan I. W. Warmada, "Karakterisasi Kandungan Mineral Dalam Bauksit Dengan Metode Xrd Semi-Kuantitatif Di Kawasan Tambang Tayan, Kalimantan Barat," Proceeing Semin. Nas. Kebumian, hlm. 612-623, 2016.

[4] M. Munasir, T. Triwikantoro, M. Zainuri, dan D. Darminto, "Uji Xrd Dan Xrf Pada Bahan Meneral (Batuan Dan Pasir) Sebagai Sumber Material Cerdas (CaCO3 dan SiO2)," J. Penelit. Fis. Dan Apl. JPFA, vol. 2, no. 1, hlm. 20-29, Jun 2012.

[5] A. A. Bunaciu, E. gabriela Udriştioiu, dan H. Y. Aboul-Enein, "X-Ray Diffraction: Instrumentation and Applications," Crit. Rev. Anal. Chem., vol. 45, no. 4, hlm. 289-299, Okt 2015.

[6] N. A. Metungku dan D. Darwis, "Pemurniaan Dan Karakterisasi Senyawa Sio2 Berbasis Pasir Kuarsa Dari Desa Pendolo Kecamatan Pamona Selatan Kabupaten Poso," Gravitasi, vol. 16, no. 1, hlm. 39-43, 2017. 